\title{
Reallocating time from device-measured sleep, sedentary behaviour or light physical activity to moderate-to-vigorous physical activity is associated with lower cardiovascular disease risk
}

Rosemary Walmsley MMathPhil ${ }^{1,2}$, Shing Chan $\mathrm{PhD}^{1,2}$, Karl Smith-Byrne DPhil ${ }^{3}$, Rema Ramakrishnan $\mathrm{PhD}^{4}$, Mark Woodward $\mathrm{PhD}^{5,6,7}$, Kazem Rahimi FRCP ${ }^{4,8,9,10}$, Terence Dwyer $\mathrm{MD}^{4,11}$, Derrick Bennett $\mathrm{PhD}^{* 2,8}$, Aiden Doherty $\mathrm{PhD}^{* 1,2,8}$

${ }^{*}$ Contributed equally; Corresponding authors.

Correspondence address: aiden.doherty@ndph.ox.ac.uk, derrick.bennett@ndph.ox.ac.uk

+44 (0)1865 617794, Nuffield Department of Population Health, University of Oxford, Oxford, UK

${ }^{1}$ Big Data Institute, Li Ka Shing Centre for Health Information and Discovery, University of Oxford, Oxford, UK

${ }^{2}$ Nuffield Department of Population Health, University of Oxford, Oxford, UK

${ }^{3}$ International Agency for Research on Cancer, Genetic Epidemiology Group

${ }^{4}$ Nuffield Department of Women's and Reproductive Health, University of Oxford, Oxford, UK

${ }^{5}$ The George Institute for Global Health, School of Public Health, Imperial College London, London, UK

${ }^{6}$ The George Institute for Global Health, University of New South Wales, Sydney, Australia

${ }^{7}$ Department of Epidemiology, Johns Hopkins University, Baltimore, USA

${ }^{8}$ National Institute of Health Research Oxford Biomedical Research Centre, Oxford University Hospitals NHS Foundation Trust, John Radcliffe Hospital, Oxford, UK

${ }^{9}$ Deep Medicine, Oxford Martin School, University of Oxford, Oxford, UK

${ }^{10}$ Oxford University Hospitals NHS Foundation Trust, Oxford, UK

${ }^{11}$ Murdoch Children’s Research Institute, Melbourne, Australia

NOTE: This preprint reports new research that has not been certified by peer review and should not be used to guide clinical practice. 
medRxiv preprint doi: https://doi.org/10.1101/2020.11.10.20227769; this version posted November 20, 2020. The copyright holder for this preprint (which was not certified by peer review) is the author/funder, who has granted medRxiv a license to display the preprint in

It is made available under a CC-BY 4.0 International license .

\begin{abstract}
Background

Moderate-to-vigorous physical activity (MVPA), light physical activity, sedentary behaviour and sleep have all been associated with cardiovascular disease (CVD). Due to challenges in measuring and analysing movement behaviours, there is uncertainty about how the association with incident CVD varies with the time spent in these different movement behaviours.
\end{abstract}

\title{
Methods
}

We developed a machine-learning model (Random Forest smoothed by a Hidden Markov model) to classify sleep, sedentary behaviour, light physical activity and MVPA from accelerometer data. The model was developed using data from a free-living study of 152 participants who wore an Axivity AX3 accelerometer on the wrist while also wearing a camera and completing a time use diary. Participants in UK Biobank, a prospective cohort study, were asked to wear an accelerometer (of the same type) for seven days, and we applied our machine-learning model to classify their movement behaviours. Using Compositional Data Analysis Cox regression, we investigated how reallocating time between movement behaviours was associated with CVD incidence.

\section{Findings}

We classified accelerometer data as sleep, sedentary behaviour, light physical activity or MVPA with a mean accuracy of $88 \%(95 \%$ CI: 87,89$)$ and Cohen's kappa of $0 \cdot 80$ (95\% CI: $0 \cdot 79,0 \cdot 82)$. Among 87,509 UK Biobank participants, there were 3,424 incident CVD events. Reallocating time from any behaviour to MVPA, or reallocating time from sedentary behaviour to any behaviour, was associated with a lower risk of CVD. For example, for a hypothetical average individual, reallocating 20 minutes/day to MVPA from all other behaviours proportionally was associated with $9 \%(7 \%, 10 \%)$ lower risk of incident CVD, while reallocating 1 hour/day to sedentary behaviour was associated with $5 \%(3 \%, 7 \%)$ higher risk.

\section{Interpretation}

Reallocating time from light physical activity, sedentary behaviour or sleep to MVPA, or reallocating time from sedentary behaviour to other behaviours, was associated with lower risk of incident CVD. Accurate classification of movement behaviours using machine-learning and statistical methods to address the compositional nature of movement behaviours enabled these insights. Public health interventions and guidelines should promote reallocating time to MVPA from other behaviours, as well as reallocating time from sedentary behaviour to light physical activity.

\section{Funding}

Medical Research Council. 
medRxiv preprint doi: https://doi.org/10.1101/2020.11.10.20227769; this version posted November 20, 2020. The copyright holder for this preprint (which was not certified by peer review) is the author/funder, who has granted medRxiv a license to display the preprint in

\section{Research in Context}

\section{Evidence before this study}

Low levels of moderate-to-vigorous physical activity, low levels of light physical activity, high levels of sedentary behaviour and short and long sleep time have been associated with cardiovascular disease risk. Uncertainty remains about how different combinations of behaviours are associated with risk, in part due to challenges in the measurement (e.g. reliance on self-reported measures or crude devicebased measures) and analysis of movement behaviours (e.g. taking appropriate account of behaviours making up the 24 hour day). We searched PubMed for studies published up to the end of September 2020 that investigated the association between device-measured moderate-to-vigorous physical activity, light physical activity, sedentary behaviour or sleep and incident cardiovascular disease in adult populations (search terms in Supplementary Material). Four studies were identified, which found that lower levels of sedentary behaviour, higher levels of light physical activity and higher levels of moderate-to-vigorous physical activity were associated with lower cardiovascular disease risk. These studies did not consider sleep and used traditional 'cut-point' based methods to identify movement behaviours in device data. Most categorised the exposure and adjusted only partially for time in behaviours other than the behaviour of interest.

\section{Added value of this study}

In this prospective study of 87,509 participants, we used machine-learning methods, developed and validated using a separate free-living dataset, to accurately classify device data as sleep, sedentary behaviour, light physical activity or moderate-to-vigorous physical activity. We used a Compositional Data Analysis approach to investigate how reallocating time between device-measured movement behaviours was associated with cardiovascular disease incidence. We found that, for a hypothetical average individual, reallocating 20 minutes/day to moderate-to-vigorous physical activity from all other behaviours proportionally was associated with $9 \%(95 \% \mathrm{CI}$ : 7\%, 10\%) lower risk of incident cardiovascular disease, whereas reallocating 1 hour/day to sedentary behaviour was associated with $5 \%$ $(3 \%, 7 \%)$ higher risk. 
medRxiv preprint doi: https://doi.org/10.1101/2020.11.10.20227769; this version posted November 20, 2020. The copyright holder for this preprint (which was not certified by peer review) is the author/funder, who has granted medRxiv a license to display the preprint in perpetuity.
It is made available under a CC-BY 4.0 International license.

\section{Implications of all the available evidence}

Emerging methods, such as machine-learning based behaviour classification and Compositional Data Analysis for epidemiological analysis, can provide new health insights. Using these methods we found that reallocating time to moderate-to-vigorous physical activity from other behaviours was associated with lower cardiovascular disease risk and thus should be encouraged. Reallocating time from sedentary behaviour to other behaviours was also associated with lower cardiovascular risk. To strengthen the evidence for causality, intervention studies should examine the health consequences of reallocating time between movement behaviours. 
medRxiv preprint doi: https://doi.org/10.1101/2020.11.10.20227769; this version posted November 20, 2020. The copyright holder for this

\section{Introduction}

Previous studies have shown low levels of light physical activity ${ }^{1}$ and moderate-to-vigorous physical $\operatorname{activity}^{2}$ (MVPA) and high levels of sedentary behaviour ${ }^{3}$ are positively associated with cardiovascular risk, whereas for sleep a U-shaped association has been found. ${ }^{4,5}$ Due to challenges in measuring and analysing movement behaviours, there is uncertainty about how different combinations of movement behaviours are related to cardiovascular disease (CVD) risk.

Recall and reporting bias affect self-reported measurements, ${ }^{6}$ and some behaviours (e.g. light physical activity) are hard to capture. ${ }^{7}$ Device-based measurements address these concerns but introduce new challenges. Many studies use hip-worn devices, where mean wear time is typically $<15$ hours/day and sleep is not measured. ${ }^{8}$ Behaviours have typically been classified using 'cut-point' based methods, which use an acceleration threshold to distinguish behaviours. ${ }^{9}$ These methods can only distinguish a limited set of behaviours and are prone to substantial misclassification. ${ }^{9-11}$ Emerging machine-learning methods could allow a wider range of behaviours to be classified accurately, ${ }^{9-11}$ providing they are developed and validated using free-living datasets (rather than laboratory-based data). ${ }^{9-11}$

There is uncertainty about how movement behaviours are associated with CVD, as analyses often neglect the fact that behaviours occur alongside one another (e.g. individuals spending large amounts of time sedentary may also typically spend small amounts of time in light physical activity). In analyses where movement behaviours are not mutually adjusted for, residual confounding is likely. Further complicating this, a person who increases time spent in one behaviour must compensate by decreasing time spent in others. This means that analyses should address the effect of reallocating time between behaviours ('isotemporal substitution'). ${ }^{12}$ It also means that movement behaviour data is compositional data, whereby only the relative time spent in different behaviours (and not the absolute time in each behaviour) is informative. ${ }^{13,14}$ An individual cannot increase time spent in light physical activity while holding time in other behaviours fixed. However, they can increase time spent in light physical activity relative to other behaviours, while holding each of those behaviours fixed as a proportion of the remaining day. Methods for analysing compositional data aim to capture and model the relative values of variables..$^{13,14}$

The objective of this study was to investigate the association between device-measured movement behaviours and risk of incident CVD in middle- to older-aged adults by:

(i) Using free-living 'ground truth' data to develop and validate a machine-learning model to classify movement behaviours from wrist-worn accelerometer data.

(ii) Applying this new model to classify movement behaviours of 87,509 UK Biobank participants who wore an accelerometer. 
medRxiv preprint doi: https://doi.org/10.1101/2020.11.10.20227769; this version posted November 20, 2020. The copyright holder for this preprint (which was not certified by peer review) is the author/funder, who has granted medRxiv a license to display the preprint in

It is made available under a CC-BY 4.0 International license.

(iii) Characterising the association between device-measured movement behaviours and incident CVD, accounting for the compositional nature of movement behaviours.

\section{Methods}

\section{UK Biobank: a large prospective cohort study}

UK Biobank is a population-based prospective cohort study of over 500,000 participants in England, Scotland and Wales (protocol available at https://www.ukbiobank.ac.uk/key-documents/). Between 2006 and 2010, individuals aged 40-69 living within roughly 25 miles of an assessment centre were recruited by letter (all eligible individuals were identified from National Health Service records; response rate 5.5\%). ${ }^{15}$ At baseline, participants attended an assessment involving a touchscreen questionnaire, biological sampling, an interview by a trained interviewer, and anthropometric measurements. ${ }^{15}$ UK Biobank received ethical approval from the National Health Service National Research Ethics Service (Ref 11/NW/0382).

\section{Device-based measures of movement behaviours in UK Biobank}

Between June 2013 and December 2015, participants with a valid email address (excluding North West region due to participant burden concerns) were invited to wear an accelerometer. 106,053 consenting participants were sent an Axivity AX3 wrist-worn triaxial accelerometer to be worn on the dominant wrist for seven days. ${ }^{16} \mathrm{~A}$ readable accelerometer dataset was obtained from 103,684 participants. Initial data processing followed established methods: ${ }^{16}$ participants were excluded if the device could not be calibrated, if they had less than three days of data or did not have data in each one hour period of the 24 hour cycle (with non-wear time defined as unbroken episodes of at least 60 minutes during which standard deviation of each axis of acceleration was less than $13.0 \mathrm{mg}^{16}$ ), if more than $1 \%$ of readings were 'clipped' (fell outside the device's dynamic range of $\pm 8 \mathrm{~g}$ ) before or after calibration, or if the average acceleration was implausibly high $(>100 \mathrm{mg}) .{ }^{16}$ Recording interruptions and non-wear time were imputed as the mean behaviour in the corresponding minute of the day on remaining days.

\section{Classification of movement behaviours using machine-learning methods}

\section{CAPTURE-24}

CAPTURE-24, an accelerometer validation study of 152 adults aged 18-91 recruited by advertisements in Oxford, UK, in 2014-2015, ${ }^{11}$ was used to develop machine-learning classification methods. Participants were asked to wear an Axivity AX3 wrist-worn accelerometer for 24 hours, wear a Vicon Autographer wearable camera while awake during that period, and keep a time use diary. ${ }^{10}$ Using camera images and time use diaries, trained annotators annotated accelerometer data with labels from the Compendium of Physical Activities. ${ }^{17}$ Fine-grained labels were mapped to sleep, sedentary behaviour, light physical activity, and MVPA (see Supplementary Material and Table S1). 
medRxiv preprint doi: https://doi.org/10.1101/2020.11.10.20227769; this version posted November 20, 2020. The copyright holder for this preprint (which was not certified by peer review) is the author/funder, who has granted medRxiv a license to display the preprint in

It is made available under a CC-BY 4.0 International license.

Describing intensity in METs (Metabolic Equivalent of Task), which measure energy expenditure relative to energy expenditure in quiet sitting, these behaviours were defined as:

1. Sleep: non-waking behaviour.

2. Sedentary behaviour: waking behaviour at $<1 \cdot 5$ METs in a sitting, lying or reclining posture. ${ }^{18}$

3. Light physical activity: waking behaviour at $<3$ METs not meeting the sedentary behaviour definition.

4. MVPA: all behaviour at $\geq 3$ METs. ${ }^{17}$

CAPTURE-24 received ethical approval from the University of Oxford Inter-Divisional Research Ethics Committee (Ref SSD/CUREC1A/13-262).

\section{Machine-learning for behaviour classification}

Using this labelled data from the CAPTURE-24 study, a balanced Random Forest with 100 decision trees was trained to classify the behaviour in 30 -second time windows using 50 rotation-invariant time and frequency domain features of the accelerometer signal (Table S2). As the Random Forest did not use time sequence information, the behaviour sequence was smoothed using a Hidden Markov model. This model treated the Random-Forest-predicted behaviours as 'emissions' from an underlying true behaviour sequence, and used the Viterbi algorithm to identify the most likely underlying true sequence given the observed sequence ${ }^{19}$. Transition probabilities between different behaviours were determined using camera validation data, and probability of the Random Forest predicting each behaviour conditional on the true behaviour was estimated using out-of-bag estimates from the Random Forest. This model structure closely followed our previous work, ${ }^{10,11}$ and more detail is given in the Supplementary Material.

Performance was evaluated using Leave-One-Participant-Out Cross-Validation. Accuracy was used to assess overall agreement between annotator-assigned 'ground truth' labels and model-assigned labels, and Cohen's kappa was used to assess agreement beyond that expected by chance. Precision and recall were used to assess performance on each behaviour, and the confusion matrix was used to show classification patterns for examples of each behaviour. Accuracy, Cohen's kappa, precision and recall were calculated for each participant individually, and we computed their mean (across participants). To examine how sensitive mean precision and recall were to the results of participants with few examples of a behaviour, the mean was recalculated excluding participants with up to 20 minutes of a particular behaviour (the Supplementary Material contains more detail on performance evaluation). Face validity of the behaviour classification method applied to UK Biobank data was assessed by plotting the behaviour profile of UK Biobank participants across the day. 
medRxiv preprint doi: https://doi.org/10.1101/2020.11.10.20227769; this version posted November 20, 2020. The copyright holder for this preprint (which was not certified by peer review) is the author/funder, who has granted medRxiv a license to display the preprint in

It is made available under a CC-BY 4.0 International license .

\section{Ascertainment of cardiovascular disease endpoints}

UK Biobank has ongoing passive follow-up via linkage to Hospital Episode Statistics (HES; hospital diagnoses from the National Health Service, the provider of almost all UK healthcare), and the UK death register. ${ }^{15}$ Cardiovascular disease was defined as ICD-10 codes $20-25$ (ischaemic heart diseases) or I60-69 (cerebrovascular diseases) appearing in HES or on the death register. Participants with cardiovascular disease prior to accelerometer wear, either HES-recorded or self-reported in the baseline questionnaire, were excluded. Participants who did not experience a cardiovascular disease outcome were censored at death or the end of the study period as appropriate (30/06/2020 for participants in England, 29/02/2016 for participants in Wales and 31/10/2016 for participants in Scotland).

\section{Compositional Data Analysis for movement behaviour data}

A Compositional Data Analysis approach was used in the statistical analyses. This approach uses log-ratios (log-transformed ratios between movement behaviours) to describe and adjust for the movement behaviour composition. By using ratios between behaviours, the relative time in different behaviours, rather than the absolute time in any given behaviour, is modelled. For this analysis, we used isometric log-ratio pivot coordinates, a particular set of log-ratios which is widely used in movement behaviour research (see Supplementary Material for more detail). ${ }^{14,20}$

Our results are described by isotemporal substitution plots, which show the hazard ratio associated with reallocating time from one behaviour to another behaviour, and by the hazard ratio associated with particular reallocations of time between behaviours (e.g. reallocating 1 hour/day to sedentary behaviour from all other behaviours proportionally). ${ }^{21}$ These hazard ratios are relative to the mean behaviour composition among included participants, so can be interpreted as showing the outcome associated with reallocating time between behaviours for a hypothetical average individual.

\section{Statistical analyses}

Multivariable-adjusted Cox proportional hazards regression models, with age as the timescale, were used to investigate the association between the movement behaviour composition and incident cardiovascular disease. To address potential sources of confounding, the main analysis was stratified by sex and adjusted for ethnicity (Asian, Black, Other, White), smoking status (current, ex- or never smoker), frequency of alcohol consumption (never, $<3$ times/week, $3+$ times/week), fresh fruit and vegetable consumption $(<3,3-4.9,5-7.9,8+$ servings/day), frequency of red and processed meat consumption $(<1,1-1 \cdot 9,2-3.9,4+$ times/week), frequency of oily fish consumption $(<1,1,2-4,>4$ times/week), education (school leaver, further education, higher education) and deprivation (quarter of Townsend Deprivation Index in the study population). A minimally adjusted analysis was stratified by sex and used age as the timescale but had no further adjustment for potential confounders. To investigate the impact of BMI an additional analysis was adjusted for BMI as a continuous variable. A further 
medRxiv preprint doi: https://doi.org/10.1101/2020.11.10.20227769; this version posted November 20, 2020. The copyright holder for this preprint (which was not certified by peer review) is the author/funder, who has granted medRxiv a license to display the preprint in

It is made available under a CC-BY 4.0 International license.

multivariable-adjusted analysis was performed with fatal cardiovascular events as the outcome. All adjustment variables were measured at baseline assessment (Table S3 gives more details on all variables used in the analysis), and variables were not adjusted for if they were likely mediators of the association between movement behaviours and cardiovascular disease.

Participants with missing data in any adjustment variable were excluded. The proportional hazards assumption was tested component-wise and globally using the Grambsch-Therneau test with the Kaplan-Meier transformation, ${ }^{20}$ and there was no evidence (at the $5 \%$ level) that it was violated in the main analysis. Plots of the Schoenfeld residuals were also examined. Results were reported according to STROBE guidelines, ${ }^{22}$ and all confidence intervals are $95 \%$ confidence intervals. Software is described in Supplementary Material.

\section{Sensitivity analyses}

The impact of reverse causality was assessed first by excluding the initial two years of follow-up and any events within it. A further analysis additionally excluded participants who self-reported poor health or use of diabetes or cardiovascular disease-related medications at baseline or who had a prior hospital admission for any condition of the circulatory system (I00-I99 as a primary diagnosis e.g. admission for heart failure or aortic aneurysm).

To investigate unmeasured and residual confounding we used a negative control outcome of accidents without a plausible mechanistic link to movement behaviours (accidents excluding falls, cycling accidents and intentional self-harm; see Table S3) ${ }^{23} \mathrm{We}$ also used E-values to assess the minimum strength of association that an unmeasured confounder would need with both exposure and outcome to explain away the observed association (see Supplementary Material). ${ }^{24,25}$

\section{Role of the funding source}

The funding organisations had no role in design or conduct of the study; collection, management, analysis, and interpretation of the data; preparation, review, or approval of the manuscript; or decision to submit the manuscript for publication. All authors had full access to the full data in the study and accept responsibility for the decision to submit for publication.

\section{Results}

\section{Movement behaviour classification in the training dataset}

Our machine-learning method accurately classified movement behaviours in accelerometer data: when evaluated using Leave-One-Participant-Out Cross-Validation in the CAPTURE-24 study (Table S4), mean per-participant accuracy was $88 \%(95 \%$ CI: 87, 89) and mean per-participant Cohen's kappa was $0 \cdot 80$ (95\% CI: $0 \cdot 79,0 \cdot 82)$. Mean per-participant precision and recall for each behaviour show most examples of all behaviours were correctly classified, with highest performance for sleep (Figure S1). 
medRxiv preprint doi: https://doi.org/10.1101/2020.11.10.20227769; this version posted November 20, 2020. The copyright holder for this preprint (which was not certified by peer review) is the author/funder, who has granted medRxiv a license to display the preprint in

It is made available under a CC-BY 4.0 International license.

Misclassifications were most common between similar behaviours (Table S5). As expected, classification performance was worse on individuals with very few true examples of a behaviour (Figure S1). The behaviour classification showed high face validity when applied to UK Biobank participants' data (Figure S2).

\section{Analyses in the UK Biobank}

\section{Baseline characteristics}

After excluding participants with poor quality accelerometer data, participants with prevalent disease and participants with missing data, 87,509 UK Biobank participants were included in the Cox regression analysis for incident cardiovascular disease (Figure 1).

The mean composition of movement behaviours (the daily movement behaviours of a hypothetical average individual) was 8.8 hours/day sleep, 9.3 hours/day sedentary behaviour, 5.6 hours/day light physical activity and 21 minutes/day MVPA (Figure 2).

When considering movement behaviours according to participant characteristics, notable differences included that women had higher levels of light physical activity than men, and lower sedentary time and MVPA (Table 1). Older participants spent less time in MVPA than younger participants (Table 1). Participants with higher BMI spent less time in light physical activity and MVPA than participants with lower BMI, and spent more time sedentary (Table 1).

\section{Associations with incident cardiovascular disease}

Over 445,752 person years of follow-up (median 5.4 years, maximum 7.1 years), there were 3,424 incident cardiovascular disease events. Reallocating time from sedentary behaviour to light physical activity was associated with a lower risk of cardiovascular disease (Figure 3a): for a hypothetical average individual, the hazard ratio (HR) associated with reallocating 1 hour/day from light physical activity to sedentary behaviour was 1.04 (95\% CI: $1 \cdot 01,1 \cdot 06)$, while the HR associated with reallocating 1 hour/day from sedentary behaviour to light physical activity was $0.96(0.94,0.98)$. Reallocating time from sedentary behaviour to MVPA was associated with more pronounced lower risk of cardiovascular disease (Figure 3b): for an average individual, the HR associated with reallocating 15 minutes/day from MVPA to sedentary behaviour was $1 \cdot 19(1 \cdot 16,1 \cdot 23)$, while the HR associated with reallocating 15 minutes/day from sedentary behaviour to MVPA was $0.92(0.91,0.94)$. Reallocating time from light physical activity to MVPA was also associated with a lower risk of cardiovascular disease (Figure 3c).

We found that, for an average individual, reallocating 20 minutes/day to MVPA from all other behaviours proportionally was associated with $9 \%(7 \%, 10 \%)$ lower risk of cardiovascular disease (Figure 4; $28 \%$ of the study population exceeded this level of MVPA). Reallocating 1 hour/day to sedentary behaviour, from all other behaviours proportionally, was associated with $5 \%(3 \%, 7 \%)$ higher 
medRxiv preprint doi: https://doi.org/10.1101/2020.11.10.20227769; this version posted November $20,2020$. The copyright holder for this preprint (which was not certified by peer review) is the author/funder, who has granted medRxiv a license to display the preprint in

It is made available under a CC-BY 4.0 International license.

risk of cardiovascular disease (Figure 4; 26\% of the study population exceeded this level of sedentary behaviour). Reallocating 1 hour/day to light physical activity, from all other behaviours proportionally, was not significantly associated with cardiovascular disease risk (Figure 4).

Results from the multivariable-adjusted model were only slightly attenuated compared to those from a minimally adjusted model (Figure S4). Further adjustment for BMI showed that there was some attenuation of the association between movement behaviours and incident cardiovascular disease (Figure S5). For example, the $9 \%(7 \%, 10 \%)$ lower risk of cardiovascular disease associated with reallocating 20 minutes/day to MVPA, was reduced to a 7\% (5\%, 9\%) lower risk after adjustment for BMI. Associations for fatal cardiovascular events were similar to those for all cardiovascular events, with some suggestion that reallocating time from sedentary behaviour to light physical activity was more strongly associated with fatal events (Figure S6).

Removing the first two years of follow-up attenuated all associations only minimally (Figure S7). Further restricting to a healthy subgroup had only a small effect on most associations, but the association for reallocating time from sedentary behaviour to light physical activity was substantially attenuated (Figure S7).

Analyses suggested residual and unmeasured confounding had a modest impact on the main findings. Specifically, some movement behaviours were associated with the negative control outcome, suggesting a small impact of residual confounding (Figure S8). The E-values indicated that a substantial degree of unmeasured confounding would be required to reduce the observed associations to the null (Figure S9). For example, the E-value of 1.42 (for reallocating 20 minutes/day to MVPA, from all other behaviours) shows an unmeasured confounder would need to be associated with at least a 1.42-fold increase in risk for both exposure and outcome to explain away the observed association.

\section{Discussion}

We found that reallocating time to MVPA from sleep, sedentary behaviour or light physical activity or reallocating time from sedentary behaviour to light physical activity or sleep was associated with lower risk of cardiovascular disease. Per minute, the most pronounced differences in risk were seen for MVPA. For a hypothetical average individual, reallocating 20 minutes/day to MVPA from all other behaviours proportionally was associated with $9 \%(7 \%, 10 \%)$ lower risk of cardiovascular disease. In contrast, reallocating 1 hour/day to sedentary behaviour, from all other behaviours proportionally, was associated with $5 \%(3 \%, 7 \%)$ higher risk. BMI explained a modest proportion of the association between movement behaviours and incident cardiovascular disease.

Our findings extend previously reported results by showing how reallocating time between behaviours is associated with cardiovascular risk (after adjustment for other behaviours). The results of this study are consistent with our previous results, which showed a dose-response association across quartiles of 
medRxiv preprint doi: https://doi.org/10.1101/2020.11.10.20227769; this version posted November $20,2020$. The copyright holder for this

device-measured moderate physical activity for cardiovascular events in the UK Biobank (with 54\% lower risk in the highest quartile for moderate physical activity compared to the lowest) ${ }^{26}$ They are also consistent with results from a study of community-dwelling older women in the US, which found 69\% higher risk of incident cardiovascular disease in the highest quartile for device-measured sedentary behaviour compared to the lowest, ${ }^{27}$ and $22 \%$ lower risk of incident cardiovascular disease in the highest quartile for light physical activity compared to the lowest. ${ }^{11}$ While we are not aware of previous applications of a Compositional Data Analysis approach in the context of incident cardiovascular disease, McGregor et al investigated the association between movement behaviours and risk of death among 1,468 US adults (135 deaths) and found associations similar to our findings for cardiovascular disease mortality. ${ }^{28}$

Our machine-learning methods accurately identified movement behaviours in accelerometer data, achieving $88 \%$ (95\% CI: 87,89$)$ accuracy and Cohen's kappa of $0 \cdot 80(0 \cdot 79,0 \cdot 82)$ in free-living data. This represents an improvement on previously reported machine-learning approaches (Cohen's kappa $0 \cdot 80$ vs $0 \cdot 68$ ), likely due to careful curation of the behaviour classes in labelled data by two reviewers. ${ }^{11}$ While evidence from free-living data is scarce, our approach had better performance than has been reported for traditional 'cut-point' approaches. ${ }^{9}$ However, although comparable with UK estimates from other sources, ${ }^{29}$ sleep measurements should be interpreted cautiously: 'ground truth' labels for sleep came from a time use diary, which may identify time in bed rather than physiological sleep.

This study has several strengths, notably including the use of device-based measurements to characterise movement behaviours in a large, comprehensive prospective study. Compared to selfreported measurements of behaviour, device-based measurements are at reduced risk of recall and reporting bias, ${ }^{6}$ and they can capture behaviours such as light physical activity well. ${ }^{7}$ The use of a wristworn device with a full 24-hour wear protocol (with high compliance) allowed the full day of behaviours to be measured. ${ }^{16}$ The use of free-living data with 'ground truth' behaviour labels to develop and validate behaviour classification methods ensures they perform well in real-world settings. All methods used in this study are open-source and available for use in other wrist-worn accelerometer datasets. A major strength of the analysis in this study is the appropriate modelling of 24-hour behaviours using a Compositional Data Analysis approach. ${ }^{13,14}$

An important limitation of any observational study is the possibility of reverse causality bias. ${ }^{30}$ After removing the first two years of follow-up, associations were only slightly attenuated. However, further restricting analyses to a healthy subgroup attenuated the association for reallocating time from sedentary behaviour to light physical activity. Other associations, including those for reallocating time to MVPA, were attenuated slightly or not at all. Residual confounding also remains possible, although sensitivity analyses using a negative control outcome and E-values suggested its impact is likely to be limited. While results are presented for reallocations of time between behaviours, these are derived statistically across participants: each participant had a single measurement, so within-participant changes cannot be 
medRxiv preprint doi: https://doi.org/10.1101/2020.11.10.20227769; this version posted November 20, 2020. The copyright holder for this preprint (which was not certified by peer review) is the author/funder, who has granted medRxiv a license to display the preprint in

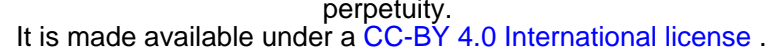

addressed directly. Validation of the machine-learning methods on another independent dataset would help to further understand their robustness. Finally, UK Biobank is not a population-representative cohort $^{15}$ (e.g. low socio-economic status individuals are under-represented compared to the national population $^{31}$ ), though a previous study showed exposure-outcome associations found in UK Biobank were similar to results in more representative samples. ${ }^{32}$

The use of machine learning and Compositional Data Analysis methods can enhance epidemiological studies using wearable device data, leading to new health insights. The results of this study support the framing of current guidelines and interventions around increasing time spent in MVPA, and reallocating time from sedentary behaviour to light physical activity where that is infeasible. ${ }^{33,34}$ To strengthen the evidence for causality, intervention studies should examine the health consequences of reallocating time between movement behaviours.

\section{Data sharing}

UK Biobank data is available to researchers who submit an application (https://www.ukbiobank.ac.uk/). The summary physical activity, sedentary behaviour, and sleep variables that we have developed will be made available as a part of the UK Biobank Returns Catalogue (https://biobank.ndph.ox.ac.uk/showcase/docs.cgi?id=1). Code for accelerometer data processing, feature extraction, machine learning, and Compositional Data Analysis is available at https://github.com/activityMonitoring.

\section{Author contributions}

$\mathrm{DB}, \mathrm{AD}, \mathrm{RW}, \mathrm{RR}, \mathrm{TD}, \mathrm{KSB}, \mathrm{MW}$, and KR conceptualised the study. RW, DB, and AD designed the analysis. SC, RW, and AD developed and implemented the machine-learning models for behaviour classification. RW conducted the statistical analysis, with advice from DB and AD. All authors contributed to the interpretation of results, and to the writing and revision of the manuscript. SC, RW, and $\mathrm{AD}$ have accessed and verified the CAPTURE-24 data. RW, SC, RR, and AD have accessed and verified the UK Biobank data.

\section{Funding}

This research has been conducted using the UK Biobank Resource under Application Number 59070. CAPTURE-24 data collection and annotation was supported by the UK Economic and Social Research Council (grant number ES/L011662/1). RW is supported by a Medical Research Council Industrial Strategy Studentship (grant number MR/S502509/1). AD, DB and KR are supported by the National Institute for Health Research (NIHR) Oxford Biomedical Research Centre (BRC). AD and SC are supported by Health Data Research UK (HDR UK), an initiative funded by UK Research and Innovation (UKRI), Department of Health and Social Care (England) and the devolved administrations, and leading medical research charities. AD and SC are supported by the Alan Turing Institute and the 
medRxiv preprint doi: https://doi.org/10.1101/2020.11.10.20227769; this version posted November 20, 2020. The copyright holder for this preprint (which was not certified by peer review) is the author/funder, who has granted medRxiv a license to display the preprint in It is made available under a CC-BY 4.0 International license .

British Heart Foundation (grant number SP/18/4/33803). MW is supported by National Health and Medical Research Foundation of Australia grants 1080206 and 1149987. KR is supported by: the PEAK Urban programme, UKRI's Global Challenge Research Fund, Grant Ref: ES/P011055/; the Oxford Martin School (OMS), University of Oxford; and the British Heart Foundation, Grant ref: PG/18/65/33872. Computation used the Oxford Biomedical Research Computing (BMRC) facility, a joint development between the Wellcome Centre for Human Genetics and the Big Data Institute supported by HDR UK and the NIHR Oxford BRC. The views expressed are those of the author(s) and not necessarily those of the UK National Health Service, the NIHR, the OMS, or the Department of Health and Social Care. The funding organisations had no role in design or conduct of the study; collection, management, analysis, and interpretation of the data; preparation, review, or approval of the manuscript; or decision to submit the manuscript for publication.

\section{Declarations of Interest}

MW is a consultant to Amgen, Kyowa Kirin and Freeline. 
medRxiv preprint doi: https://doi.org/10.1101/2020.11.10.20227769; this version posted November 20, 2020. The copyright holder for this preprint (which was not certified by peer review) is the author/funder, who has granted medRxiv a license to display the preprint in

It is made available under a CC-BY 4.0 International license .

\section{References}

1 LaCroix AZ, Bellettiere J, Rillamas-Sun E, et al. Association of Light Physical Activity Measured by Accelerometry and Incidence of Coronary Heart Disease and Cardiovascular Disease in Older Women. JAMA Netw Open 2019; 2: e190419.

2 Lee IM, Shiroma EJ, Lobelo F, et al. Effect of physical inactivity on major non-communicable diseases worldwide: An analysis of burden of disease and life expectancy. Lancet 2012; $\mathbf{3 8 0}$ : $219-29$.

3 Pandey A, Salahuddin U, Garg S, et al. Continuous dose-response association between sedentary time and risk for cardiovascular disease a meta-analysis. JAMA Cardiol 2016; 1: $575-83$.

4 Itani O, Jike M, Watanab N, Kaneita Y. Short sleep duration and health outcomes: a systematic review, meta-analysis, and meta-regression. Sleep Med. Rev. 2016; 32: 246-56.

5 Jike M, Itani O, Watanabe N, Buysse DJ, Kaneita Y. Long sleep duration and health outcomes: A systematic review, meta-analysis and meta-regression. Sleep Med. Rev. 2018; 39: 25-36.

6 Sabia S, Van Hees VT, Shipley MJ, et al. Association between questionnaire-and accelerometer-assessed physical activity: The role of sociodemographic factors. Am $J$ Epidemiol 2014; 179: 781-90.

$7 \quad$ Lee I-M, Shiroma EJ. Using accelerometers to measure physical activity in large-scale epidemiological studies: issues and challenges. Br J Sports Med 2014; 48: 197-201.

8 Ekelund U, Tarp J, Steene-Johannessen J, et al. Dose-response associations between accelerometry measured physical activity and sedentary time and all cause mortality: systematic review and harmonised meta-analysis. Bmj 2019; 366: 14570.

9 Kerr J, Patterson RE, Ellis K, et al. Objective Assessment of Physical Activity: Classifiers for Public Health. Med Sci Sport Exerc 2017; 48: 951-7.

10 Willetts M, Hollowell S, Aslett L, Holmes C, Doherty A. Statistical machine learning of sleep and physical activity phenotypes from sensor data in 96,220 UK Biobank participants. Sci Rep 2018; 8: 0-10.

11 Doherty A, Smith-Byrne K, Ferreira T, et al. GWAS identifies 14 loci for device-measured physical activity and sleep duration. Nat Commun 2018; 9.

DOI:10.1093/acrefore/9780190236557.013.204.

12 Mekary RA, Willett WC, Hu FB, Ding EL. Isotemporal substitution paradigm for physical activity epidemiology and weight change. Am J Epidemiol 2009; 170: 519-27. 
medRxiv preprint doi: https://doi.org/10.1101/2020.11.10.20227769; this version posted November 20, 2020. The copyright holder for this preprint (which was not certified by peer review) is the author/funder, who has granted medRxiv a license to display the preprint in

13 Chastin SFMM, Palarea-Albaladejo J, Dontje ML, Skelton DA. Combined Effects of Time Spent in Physical Activity, Sedentary Behaviors and Sleep on Obesity and Cardio-Metabolic Health Markers: A Novel Compositional Data Analysis Approach. PLoS One 2015; 10: e0139984.

14 Dumuid D, Pedišić Ž, Palarea-Albaladejo J, Martín-Fernández JA, Hron K, Olds T. Compositional Data Analysis in Time-Use Epidemiology: What, Why, How. Int J Environ Res Public Health 2020; 17: 2220.

15 Allen N, Sudlow C, Downey P, et al. UK Biobank: Current status and what it means for epidemiology. Heal Policy Technol 2012; 1: 123-6.

16 Doherty A, Jackson D, Hammerla N, et al. Large scale population assessment of physical activity using wrist worn accelerometers: The UK biobank study. PLoS One 2017; 12: 1-14.

17 Ainsworth BE, Haskell WL, Herrmann SD, et al. 2011 compendium of physical activities: A second update of codes and MET values. Med Sci Sports Exerc 2011; 43: 1575-81.

18 Tremblay MS, Aubert S, Barnes JD, et al. Sedentary Behavior Research Network (SBRN) Terminology Consensus Project process and outcome. Int J Behav Nutr Phys Act 2017; 14: 117.

19 Forney GD. The Viterbi Algorithm. Proc IEEE 1973; 61: 268-78.

20 McGregor DE, Palarea-Albaladejo J, Dall PMP, Hron K, Chastin SFM. Cox regression survival analysis with compositional covariates: Application to modelling mortality risk from 24-h physical activity patterns. Stat Methods Med Res 2019; 29: 1447-65.

21 Dumuid D, Pedišić Ž, Stanford TE, et al. The compositional isotemporal substitution model: A method for estimating changes in a health outcome for reallocation of time between sleep, physical activity and sedentary behaviour. Stat Methods Med Res 2017; 28: 846-57.

22 Von Elm E, Altman DG, Egger M, Pocock SJ, Gøtzsche PC, Vandenbroucke JP. The Strengthening the Reporting of Observational Studies in Epidemiology (STROBE) statement: Guidelines for reporting observational studies. PLoS Med 2007.

DOI:10.1371/journal.pmed.0040296.

23 Hamer M, Bauman A, Bell JA, Stamatakis E. Examining associations between physical activity and cardiovascular mortality using negative control outcomes. Int J Epidemiol 2019; 48: 1161-6.

24 Van Der Weele TJ, Ding P. Sensitivity analysis in observational research: Introducing the EValue. Ann Intern Med 2017; 167: 268-74. 
medRxiv preprint doi: https://doi.org/10.1101/2020.11.10.20227769; this version posted November 20,2020 . The copyright holder for this preprint (which was not certified by peer review) is the author/funder, who has granted medRxiv a license to display the preprint in

It is made available under a CC-BY 4.0 International license.

E-values. Epidemiology 2018; 29: e45.

26 Ramakrishnan R, Doherty A, Smith-Byrne K, et al. Accelerometer measured physical activity and the incidence of cardiovascular disease in 90,211 UK Biobank participants. PLOS Med.(In press)

27 Bellettiere J, Lamonte MJ, Evenson KR, et al. Sedentary Behavior and Cardiovascular Disease in Older Women: The OPACH Study. Circulation 2019; 139: 1036-46.

28 McGregor DE, Palarea-Albaladejo J, Dall PM, del Pozo Cruz B, Chastin SFM. Compositional analysis of the association between mortality and 24-hour movement behaviour from NHANES. Eur J Prev Cardiol 2019; : 2047487319867783.

29 Lamote de Grignon Pérez J, Gershuny J, Foster R, De Vos M. Sleep differences in the UK between 1974 and 2015: Insights from detailed time diaries. J Sleep Res 2019; 28: e12753.

30 Strain T, Wijndaele K, Sharp SJ, Dempsey PC, Wareham N, Brage S. Impact of follow-up time and analytical approaches to account for reverse causality on the association between physical activity and health outcomes in UK Biobank. Int J Epidemiol 2019; 49: 162-72.

31 Fry A, Littlejohns TJ, Sudlow C, et al. Study Design Comparison of Sociodemographic and Health-Related Characteristics of UK Biobank Participants With Those of the General Population. 2017; 186: 1026-34.

32 Batty GD, Gale CR, Kivimäki M, Deary IJ, Bell S. Comparison of risk factor associations in UK Biobank against representative, general population based studies with conventional response rates: prospective cohort study and individual participant meta-analysis. BMJ 2020; 368: $1-8$.

33 Davies DSC, Atherton F, McBride M, Calderwood C. UK Chief Medical Officers' Physical Activity Guidelines. Dep Heal Soc Care, UK 2019; : 1-65.

34 Department of Human and Health Services. Physical Activity Guidelines for Americans, 2nd edition. 2018 https://health.gov/paguidelines/about/. 
Figure 1: Participant flow diagram for the analysis of movement behaviours and incident cardiovascular disease in UK Biobank participants.

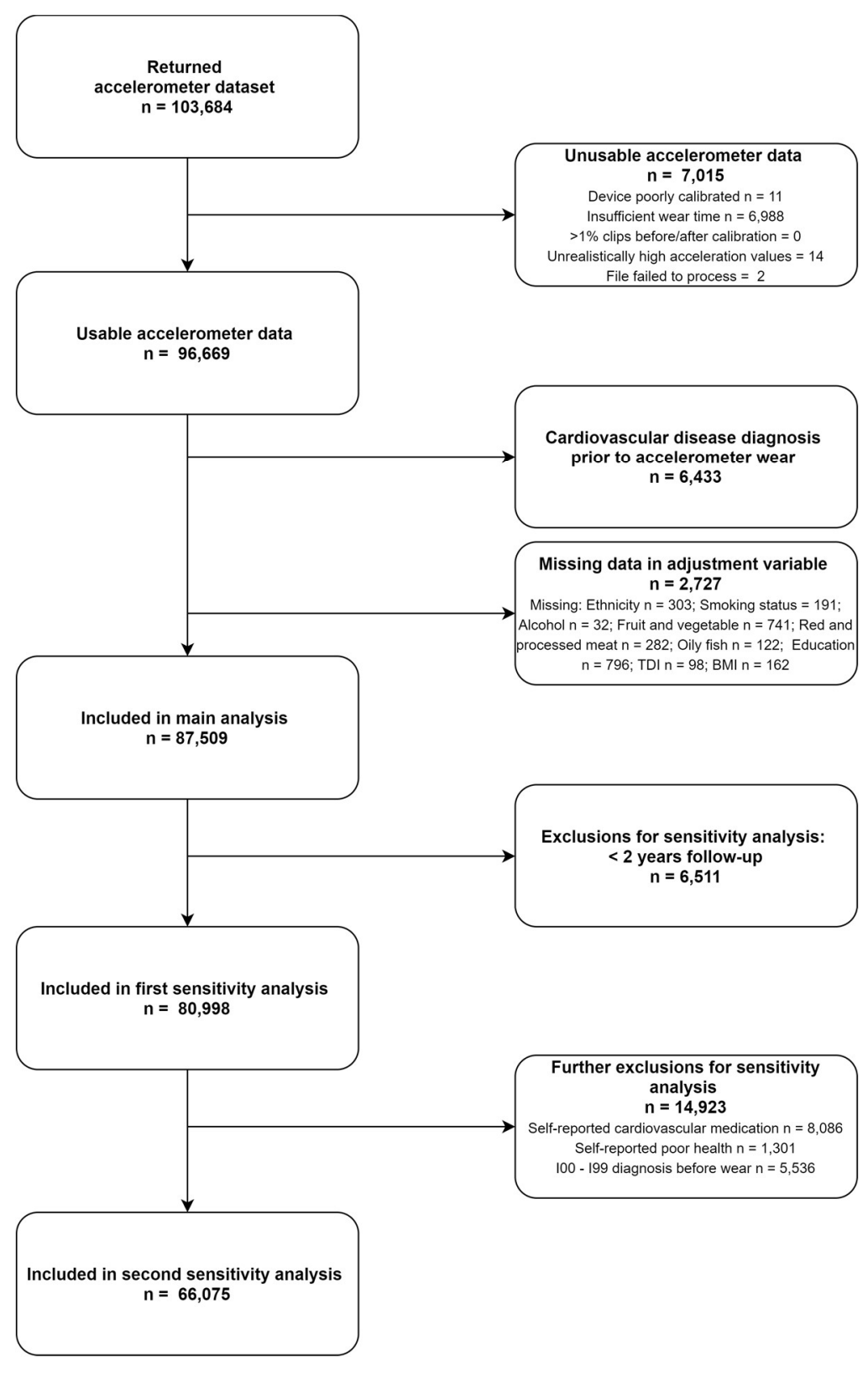




\section{Figure 2: Distribution of movement behaviours in 87,509 UK Biobank participants.}

a) Mean movement behaviour composition among UK Biobank participants. b) Movement behaviours of UK Biobank participants on a ternary density plot, showing sleep, sedentary behaviour (SB) and physical activity (PA; combines light and moderate-to-vigorous physical activity). The crosshair marks the compositional mean. $25 \%$ of participants fall between each pair of lines. The behaviour composition at a point can be found by tracing out (parallel to the white lines) from the point to the axes. c) Ternary density plot showing the behaviour distribution of the 5\% most active (blue) and 5\% least active (red) UK Biobank participants by average acceleration. $25 \%$ of participants in each group fall between each pair of lines.

a)

\section{Moderate-to-vigorous} activity:

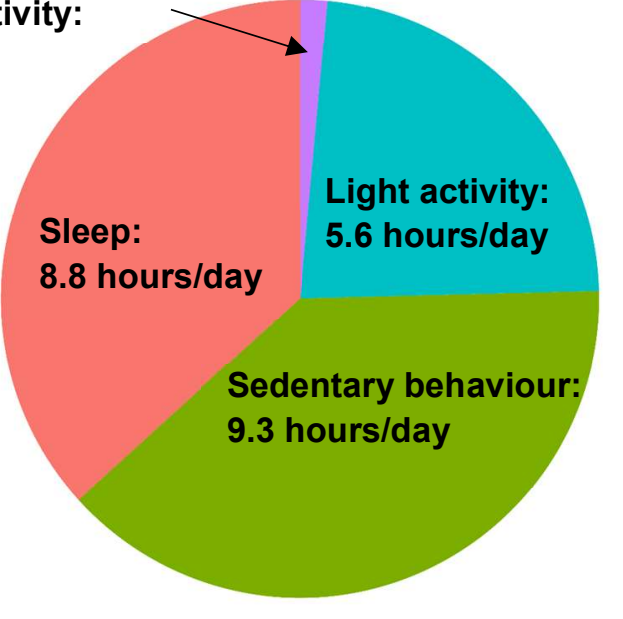

b)

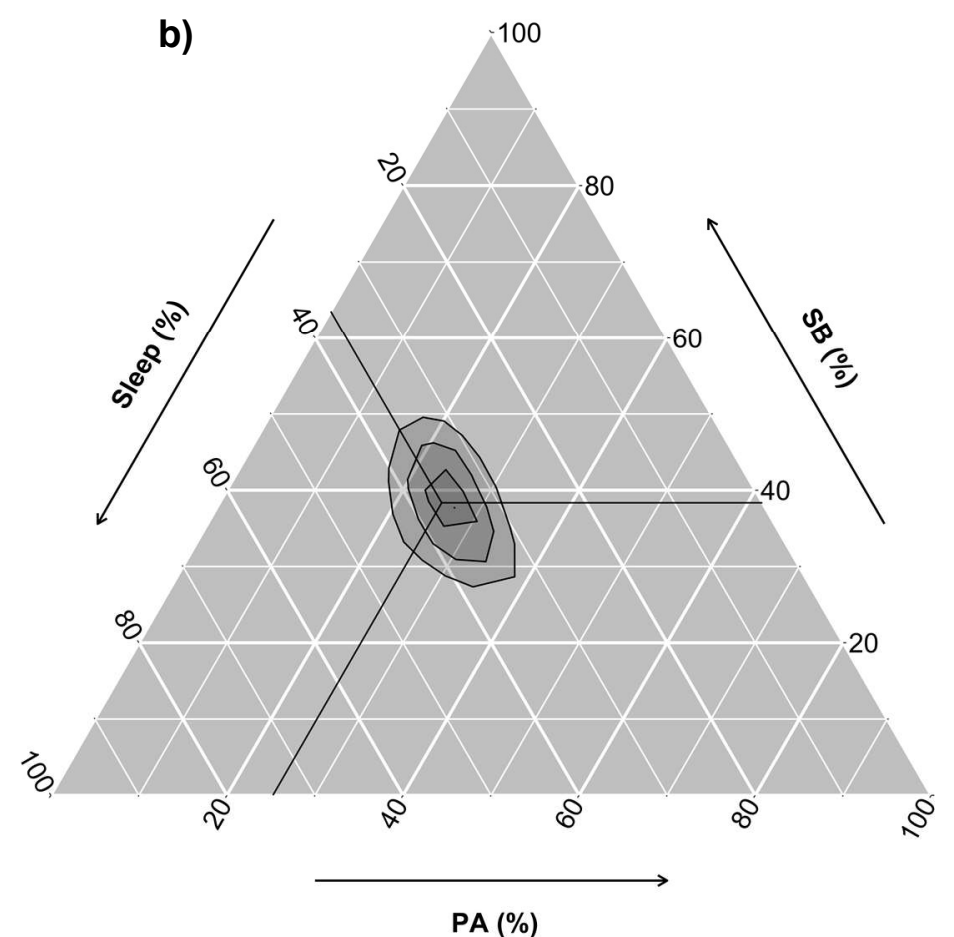

c)

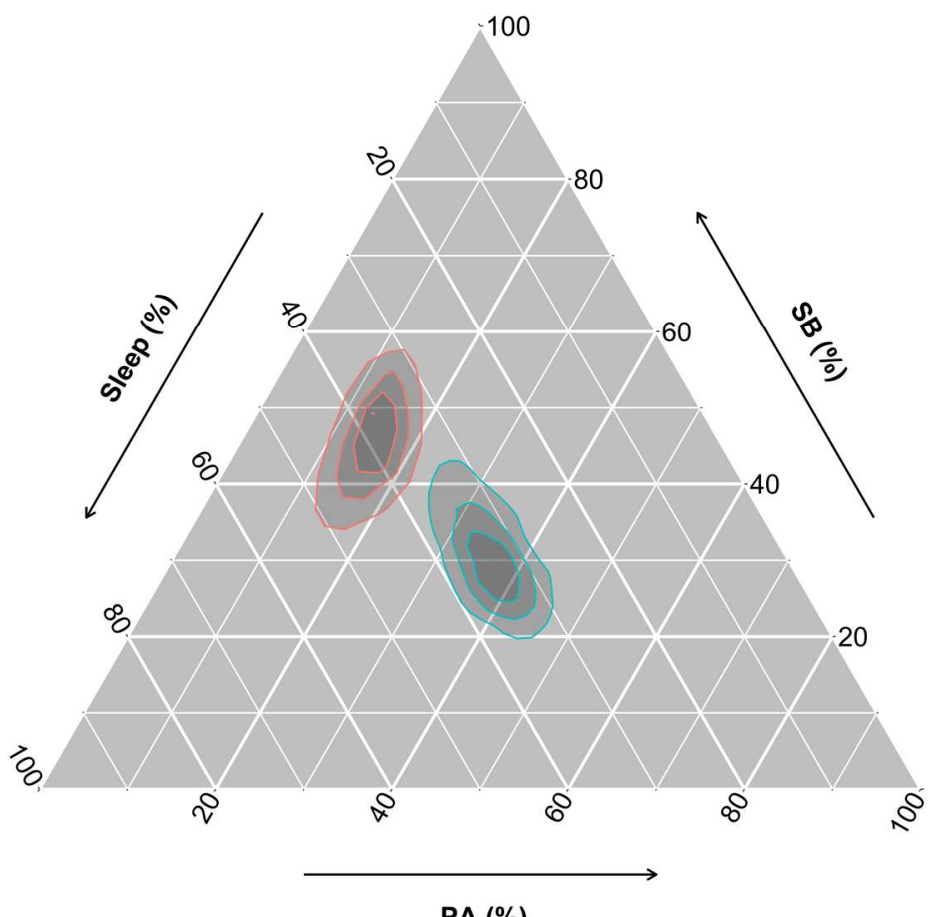

PA (\%) 
Table 1: Movement behaviours of 87,509 UK Biobank participants by participant characteristics.

\begin{tabular}{|c|c|c|c|c|c|}
\hline & n (\%) & $\begin{array}{l}\text { Sleep* } \\
\text { (hr/day) }\end{array}$ & $\begin{array}{l}\text { Sedentary behaviour* } \\
\text { (hr/day) }\end{array}$ & $\begin{array}{l}\text { Light activity* } \\
\text { (hr/day) }\end{array}$ & $\begin{array}{l}\text { Moderate-to-vigorous } \\
\text { activity* (min/day) }\end{array}$ \\
\hline Overall & $87,509(100)$ & $8 \cdot 6(7 \cdot 9,9 \cdot 3)$ & $9 \cdot 2(8 \cdot 0,10 \cdot 3)$ & $5 \cdot 6(4 \cdot 5,6 \cdot 7)$ & $25(12,44)$ \\
\hline \multicolumn{6}{|l|}{ Age, years } \\
\hline $40-49$ & $7,769(9)$ & $8 \cdot 5(7 \cdot 8,9 \cdot 1)$ & $9 \cdot 4(8 \cdot 1,10 \cdot 6)$ & $5 \cdot 4(4 \cdot 3,6 \cdot 6)$ & $30(16,50)$ \\
\hline $50-59$ & $26,084(30)$ & $8 \cdot 5(7 \cdot 8,9 \cdot 2)$ & $9 \cdot 3(8 \cdot 1,10 \cdot 5)$ & $5 \cdot 4(4 \cdot 4,6 \cdot 7)$ & $28(14,47)$ \\
\hline $60-69$ & $38,778(44)$ & $8 \cdot 6(8 \cdot 0,9 \cdot 3)$ & $9 \cdot 0(7 \cdot 9,10 \cdot 2)$ & $5 \cdot 6(4 \cdot 6,6 \cdot 7)$ & $25(12,43)$ \\
\hline $70-79$ & $14,878(17)$ & $8 \cdot 6(7 \cdot 9,9 \cdot 4)$ & $9 \cdot 2(8 \cdot 1,10 \cdot 3)$ & $5 \cdot 6(4 \cdot 5,6 \cdot 7)$ & $20(9,36)$ \\
\hline \multicolumn{6}{|l|}{ Sex } \\
\hline Female & $50,892(58)$ & $8 \cdot 6(8 \cdot 0,9 \cdot 3)$ & $8 \cdot 9(7 \cdot 8,10 \cdot 0)$ & $5 \cdot 8(4 \cdot 8,7 \cdot 0)$ & $22(10,38)$ \\
\hline Male & $36,617(42)$ & $8 \cdot 4(7 \cdot 8,9 \cdot 2)$ & $9 \cdot 6(8 \cdot 4,10 \cdot 8)$ & $5 \cdot 1(4 \cdot 1,6 \cdot 2)$ & $31(16,52)$ \\
\hline \multicolumn{6}{|l|}{ Ethnicity } \\
\hline Asian & $758(1)$ & $8 \cdot 4(7 \cdot 7,9 \cdot 3)$ & $9 \cdot 3(7 \cdot 9,10 \cdot 5)$ & $5 \cdot 6(4 \cdot 5,6 \cdot 9)$ & $19(10,35)$ \\
\hline Black & $703(1)$ & $8 \cdot 2(7 \cdot 3,9 \cdot 0)$ & $9 \cdot 4(8 \cdot 0,10 \cdot 6)$ & $5 \cdot 9(4 \cdot 8,7 \cdot 1)$ & $21(10,36)$ \\
\hline Other & $1,151(1)$ & $8 \cdot 4(7 \cdot 6,9 \cdot 1)$ & $9 \cdot 2(8 \cdot 0,10 \cdot 5)$ & $5 \cdot 7(4 \cdot 5,7 \cdot 0)$ & $26(13,44)$ \\
\hline White & $84,897(97)$ & $8 \cdot 6(7 \cdot 9,9 \cdot 3)$ & $9 \cdot 2(8 \cdot 0,10 \cdot 3)$ & $5 \cdot 6(4 \cdot 5,6 \cdot 7)$ & $25(12,44)$ \\
\hline \multicolumn{6}{|l|}{ Smoking status } \\
\hline Never smoker & $50,897(58)$ & $8 \cdot 6(7 \cdot 9,9 \cdot 3)$ & $9 \cdot 2(8 \cdot 0,10 \cdot 3)$ & $5 \cdot 6(4 \cdot 5,6 \cdot 7)$ & $26(13,45)$ \\
\hline Ex-smoker & $30,721(35)$ & $8 \cdot 5(7 \cdot 9,9 \cdot 3)$ & $9 \cdot 2(8 \cdot 0,10 \cdot 3)$ & $5 \cdot 6(4 \cdot 5,6 \cdot 7)$ & $25(12,44)$ \\
\hline Current smoker & $5,891(7)$ & $8 \cdot 6(7 \cdot 9,9 \cdot 3)$ & $9 \cdot 4(8 \cdot 2,10 \cdot 6)$ & $5 \cdot 4(4 \cdot 3,6 \cdot 6)$ & $21(9,39)$ \\
\hline \multicolumn{6}{|l|}{ Alcohol consumption } \\
\hline Never drinker & $4,746(5)$ & $8 \cdot 6(7 \cdot 9,9 \cdot 4)$ & $9 \cdot 1(7 \cdot 8,10 \cdot 3)$ & $5 \cdot 6(4 \cdot 5,6 \cdot 9)$ & $20(9,39)$ \\
\hline$<3$ times per week & $39,770(45)$ & $8 \cdot 6(7 \cdot 9,9 \cdot 3)$ & $9 \cdot 2(8 \cdot 0,10 \cdot 3)$ & $5 \cdot 6(4 \cdot 5,6 \cdot 7)$ & $23(11,41)$ \\
\hline $3+$ times per week & 42,993 (49) & $8 \cdot 5(7 \cdot 9,9 \cdot 2)$ & $9 \cdot 2(8 \cdot 0,10 \cdot 3)$ & $5 \cdot 6(4 \cdot 5,6 \cdot 7)$ & $28(14,47)$ \\
\hline \multicolumn{6}{|l|}{ Fruit and vegetable consumption } \\
\hline$<3$ servings/day & $3,594(4)$ & $8 \cdot 6(7 \cdot 8,9 \cdot 4)$ & $9 \cdot 7(8 \cdot 4,11 \cdot 0)$ & $5 \cdot 0(3 \cdot 9,6 \cdot 3)$ & $21(9,39)$ \\
\hline $3-4.9$ servings/day & $14,292(16)$ & $8 \cdot 6(7 \cdot 9,9 \cdot 3)$ & $9 \cdot 4(8 \cdot 2,10 \cdot 6)$ & $5 \cdot 3(4 \cdot 3,6 \cdot 5)$ & $24(12,42)$ \\
\hline $5-7 \cdot 9$ servings/day & $36,992(42)$ & $8 \cdot 6(7 \cdot 9,9 \cdot 3)$ & $9 \cdot 2(8 \cdot 0,10 \cdot 3)$ & $5 \cdot 6(4 \cdot 5,6 \cdot 7)$ & $26(13,44)$ \\
\hline $8+$ servings/day & $32,631(37)$ & $8 \cdot 5(7 \cdot 9,9 \cdot 2)$ & $9 \cdot 0(7 \cdot 8,10 \cdot 1)$ & $5 \cdot 7(4 \cdot 7,6 \cdot 9)$ & $26(13,45)$ \\
\hline \multicolumn{6}{|l|}{ Townsend Deprivation Index } \\
\hline Least deprived $(<-3 \cdot 8)$ & $21,912(25)$ & $8 \cdot 6(7 \cdot 9,9 \cdot 3)$ & $9 \cdot 1(7 \cdot 9,10 \cdot 3)$ & $5 \cdot 6(4 \cdot 6,6 \cdot 7)$ & $24(12,43)$ \\
\hline Second least deprived $(-3 \cdot 8$ to $-2 \cdot 5)$ & $21,846(25)$ & $8 \cdot 6(7 \cdot 9,9 \cdot 3)$ & $9 \cdot 1(8 \cdot 0,10 \cdot 3)$ & $5 \cdot 6(4 \cdot 5,6 \cdot 7)$ & $24(12,43)$ \\
\hline Second most deprived $(-2 \cdot 5$ to $-0 \cdot 2)$ & $21,874(25)$ & $8 \cdot 6(7 \cdot 9,9 \cdot 3)$ & $9 \cdot 2(8 \cdot 0,10 \cdot 3)$ & $5 \cdot 6(4 \cdot 5,6 \cdot 7)$ & $25(12,44)$ \\
\hline Most deprived $(>-0 \cdot 2)$ & $21,877(25)$ & $8 \cdot 5(7 \cdot 8,9 \cdot 2)$ & $9 \cdot 3(8 \cdot 1,10 \cdot 5)$ & $5 \cdot 4(4 \cdot 3,6 \cdot 6)$ & $27(13,47)$ \\
\hline \multicolumn{6}{|l|}{ Education } \\
\hline School leaver & $28,027(32)$ & $8 \cdot 7(8 \cdot 0,9 \cdot 4)$ & $8 \cdot 9(7 \cdot 8,10 \cdot 1)$ & $5 \cdot 7(4 \cdot 7,6 \cdot 9)$ & $20(9,37)$ \\
\hline Further education & $20,576(24)$ & $8 \cdot 6(7 \cdot 9,9 \cdot 3)$ & $9 \cdot 1(8 \cdot 0,10 \cdot 3)$ & $5 \cdot 6(4 \cdot 5,6 \cdot 7)$ & $24(11,42)$ \\
\hline Higher education & $38,906(44)$ & $8 \cdot 5(7 \cdot 8,9 \cdot 1)$ & $9 \cdot 4(8 \cdot 2,10 \cdot 5)$ & $5 \cdot 4(4 \cdot 4,6 \cdot 5)$ & $30(16,50)$ \\
\hline \multicolumn{6}{|l|}{ BMI } \\
\hline Underweight $\left(<18 \cdot 5 \mathrm{~kg} / \mathrm{m}^{2}\right)$ & $511(1)$ & $8 \cdot 5(7 \cdot 9,9 \cdot 2)$ & $8 \cdot 5(7 \cdot 2,9 \cdot 6)$ & $6 \cdot 3(4 \cdot 9,7 \cdot 3)$ & $34(19,55)$ \\
\hline Normal weight $\left(18.5-24.9 \mathrm{~kg} / \mathrm{m}^{2}\right)$ & $35,052(40)$ & $8 \cdot 6(8 \cdot 0,9 \cdot 2)$ & $8 \cdot 8(7 \cdot 7,10 \cdot 0)$ & $5 \cdot 8(4 \cdot 7,6 \cdot 9)$ & $30(16,50)$ \\
\hline Overweight $\left(25 \cdot 0-29 \cdot 9 \mathrm{~kg} / \mathrm{m}^{2}\right)$ & $35,781(41)$ & $8 \cdot 5(7 \cdot 9,9 \cdot 3)$ & $9 \cdot 3(8 \cdot 1,10 \cdot 4)$ & $5 \cdot 6(4 \cdot 4,6 \cdot 6)$ & $25(12,43)$ \\
\hline Obese $\left(30+\mathrm{kg} / \mathrm{m}^{2}\right)$ & $16,165(18)$ & $8 \cdot 5(7 \cdot 8,9 \cdot 3)$ & $9 \cdot 8(8 \cdot 5,10 \cdot 9)$ & $5 \cdot 1(4 \cdot 1,6 \cdot 3)$ & $16(7,31)$ \\
\hline
\end{tabular}

*Presented as median (Inter-Quartile Range). 
Figure 3: Hazard ratios for incident cardiovascular disease associated with balance between movement behaviours in 87,509 UK Biobank participants.* (a) sedentary behaviour (SB) and light physical activity (LIPA) (b) sedentary behaviour and moderate-to-vigorous physical activity (MVPA) and (c) light physical activity and moderate-to-vigorous physical activity.
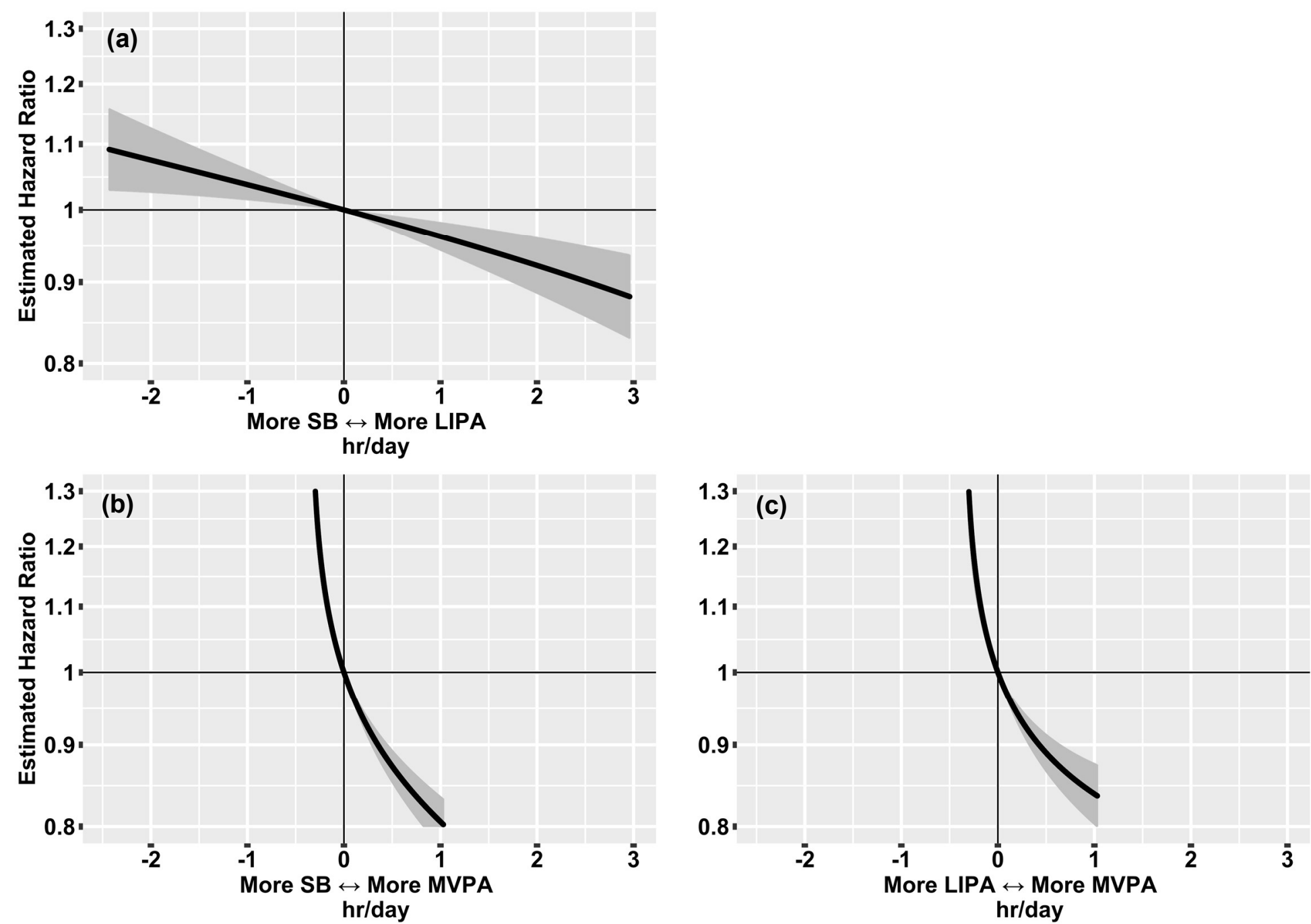

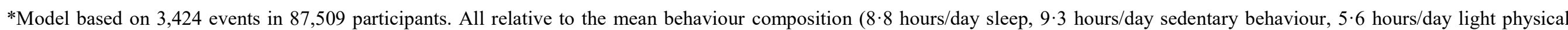

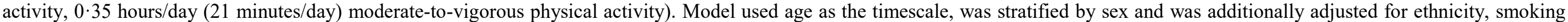
status, alcohol consumption, fresh fruit and vegetable consumption, red and processed meat consumption, oily fish consumption, deprivation and education. 
Figure 4: Hazard ratios for incident cardiovascular disease associated with reallocating time to named behaviour, from all other behaviours proportionally, in 87,509 UK Biobank participants.*

\section{Hazard Ratio}

$(95 \% \mathrm{Cl})$

REFERENCE: Mean behaviour composition

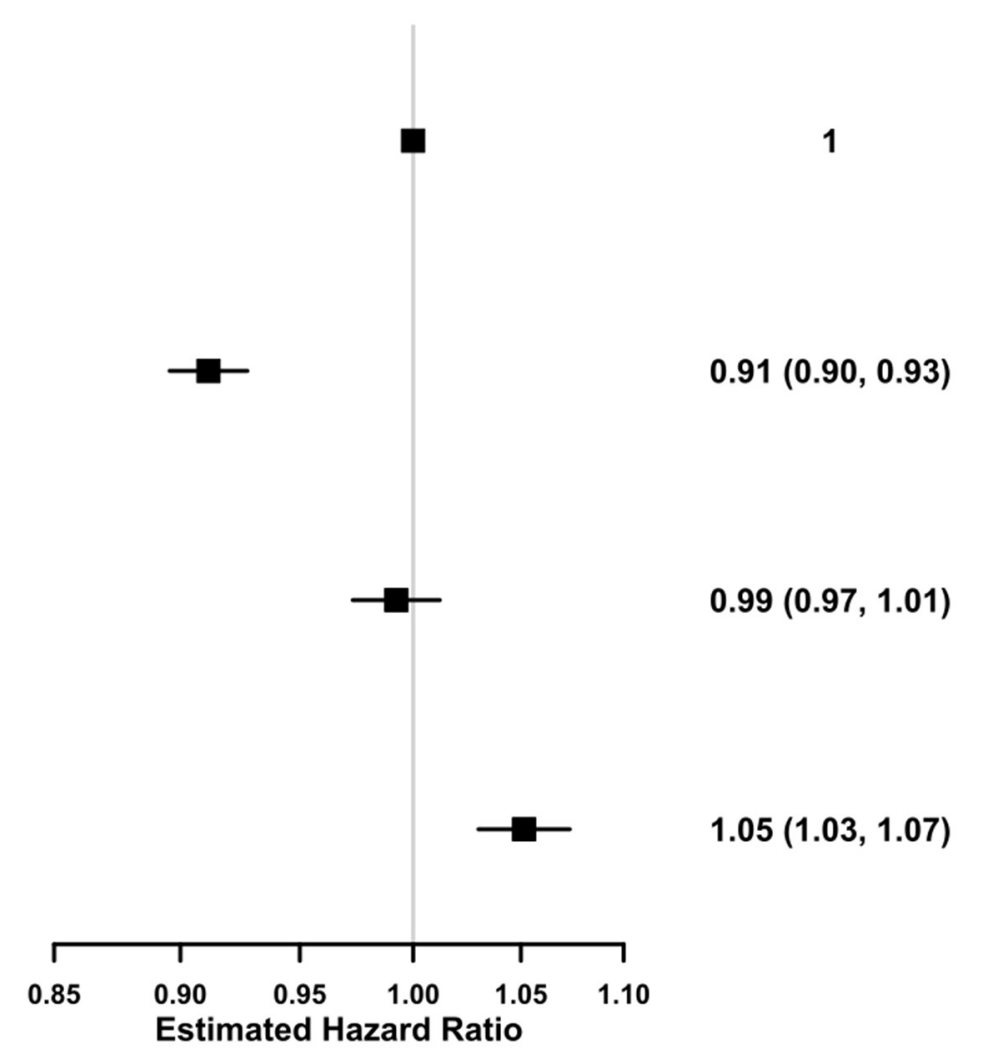

*Model based on 3,424 events in 87,509 participants. All relative to the mean behaviour composition ( $8 \cdot 8$ hours/day sleep, $9 \cdot 3$ hours/day sedentary behaviour, $5 \cdot 6$ hours/day light physical activity, 0.35 hours/day (21 minutes/day) moderate-to-vigorous physical activity) and more time in named behaviour reallocated from all other behaviours proportionally. Model used age as the timescale, was stratified by sex and was additionally adjusted for ethnicity, smoking status, alcohol consumption, fresh fruit and vegetable consumption, red and processed meat consumption, oily fish consumption, deprivation and education. 